\title{
Caracterização microbiológica, físico-química e das condições de produção e comercialização da carne de sol de Salinas, Minas Gerais
}

\author{
[Microbiological and physical-chemical characterization and conditions of production \\ and commercialization of sun-dried meat from Salinas, Minas Gerais] \\ D.C.S. Assis ${ }^{1}$, T.M. Santos ${ }^{2}$, C.B.D. Ornellas ${ }^{1}$, A.F. Drummond ${ }^{1}$, \\ F.C. Magalhães ${ }^{1}$, W.L.M. Santos ${ }^{1}$ \\ ${ }^{1}$ Escola de Veterinária - Universidade Federal de Minas Gerais - Belo Horizonte, MG \\ ${ }^{2}$ Instituto Federal do Norte de Minas Gerais - Campus Salinas - Salinas, MG
}

\begin{abstract}
RESUMO
Para avaliar as condições higiênico-sanitárias e tecnológicas (HST) de produção e comercialização da carne de sol no município de Salinas, na região Norte do estado de Minas Gerais, foram coletadas 40 amostras no comércio local para a realização de análises físico-químicas e microbiológicas. A carne de sol é produzida artesanalmente em estabelecimentos comerciais e considerada uma tradição da região. Nas análises físicoquímicas de umidade, proteína, gordura, cinzas, cloretos e $\mathrm{pH}$, foram encontrados valores médios de 70,13\%, $22,35 \%, 2,25 \%, 5,09 \%, 3,63 \%$ e 5,8, respectivamente. Duas amostras (5\%) foram positivas para Salmonella spp. e $16(40 \%)$ apresentaram contagens de $S$. aureus superiores a $10^{3} \mathrm{UFC} / \mathrm{g}$. Os valores encontrados nas análises de mesófilos aeróbicos, bolores e leveduras e coliformes totais e termotolerantes foram de 2,50x $10^{7}$ $\mathrm{UFC} / \mathrm{g}, 1,73 \times 10^{4} \mathrm{UFC} / \mathrm{g}, 9,1 \mathrm{NMP} / \mathrm{g}$ e 4,3NMP/g, respectivamente. A carne de sol produzida em Salinas é um produto artesanal, portanto heterogêneo quanto às características de produção, comercialização e de qualidade microbiológica e físico-química. A importância socioeconômica da carne de sol na região é considerável, o que justifica a necessidade de se conhecer melhor suas características para auxiliar no desenvolvimento de eventuais políticas públicas regionais visando ao controle sanitário desse produto.
\end{abstract}

Palavras-chave: carne de sol, microbiologia, físico-química

\begin{abstract}
In order to evaluate the hygienic-sanitary and technological conditions (HST) of production and commercialization of sun-dried meat, in the city of Salinas, in the North of Minas Gerais, 40 samples of the product were collected in the local commerce for carrying out physicochemical and microbiological analyses. The sun-dried meat is produced in the commercial establishments and considered a tradition of the region. In the physicochemical analyzes of moisture, protein, fat, ash content, chlorides and $\mathrm{pH}$ were found values of $70.13 \%, 22.35 \%, 2.25 \%, 5.09 \%, 3.63 \%$ and 5.8, respectively. Two samples (5\%) were positive for Salmonella spp. and $16(40 \%)$ had Staphylococcus aureus counts higher than $10^{3} \mathrm{CFU} / \mathrm{g}$. The values found for the analyses of aerobic mesophilic microorganisms, yeasts and molds and total and thermotolerant coliforms were $2.50 x$ $10^{7} \mathrm{CFU} / \mathrm{g}, 1.73 \times 10^{4} \mathrm{CFU} / \mathrm{g}, 9.1 \mathrm{MPN} / \mathrm{g}$ and $4.3 \mathrm{MPN} / \mathrm{g}$, respectively. The sun-dried meat from Salinas is a handmade product, therefore heterogeneous in terms of production, and physicochemical and microbiological quality. The socioeconomic importance of the sun-dried-meat in the region is considerable, which justifies the need to know its characteristics better to help in the development of regional public policies aiming at sanitary control of the product.
\end{abstract}

Keywords: sun-dried meat, microbiology, physicochemical

\section{INTRODUÇÃO}

A carne de sol é um produto típico das regiões Norte e Nordeste do estado de Minas Gerais,

Recebido em 11 de março de 2019

Aceito em 23 de abril de 2019

E-mail: debora@vet.ufmg.br preparada de forma artesanal, portanto não padronizada, pela adição de sal, seguida ou não da ação do sol e de ligeira desidratação pela exposição ao ar, seja durante as horas diurnas ou noturnas. Esse produto é também conhecido como carne de vento, carne de sereno, carne do sertão, 
carne-seca, carne de viagem e carne de paçoca, devido às diferenças regionais observadas durante seu preparo, relacionadas, principalmente, à forma de secagem do produto (Nóbrega e Schneider, 1983).

A carne de sol, por ser um produto artesanal (Mennucci, 2009), não possui definição própria no Regulamento da Inspeção Industrial e Sanitária de Produtos de Origem Animal (RIISPOA) e também não tem um Regulamento Técnico de Identidade e Qualidade específico (Brasil, 2017). A quantidade de sal utilizada na elaboração da carne de sol possibilita uma desidratação parcial do produto, resultando em uma vida de prateleira máxima de três a quatro dias em temperatura ambiente (Lira e Shimokomaki, 1998).

Com a publicação da Lei $\mathrm{n}^{\circ} 13.680$, de 14 de junho de 2018, o comércio interestadual de produtos alimentícios produzidos de forma artesanal foi permitido, desde que submetidos à fiscalização de órgãos de saúde pública dos estados e do Distrito Federal (Brasil, 2018). A realização de estudos para caracterização dos métodos tradicionais ou regionais próprios de preparação de cada produto, bem como das condições higiênico-sanitárias e tecnológicas (HST) da produção e comercialização, é justificada devido à grande variação nos parâmetros físico-químicos e microbiológicos, o que pode colocar em risco a saúde dos consumidores.

Apesar de representar um importante papel na economia da região Norte do estado, a literatura científica sobre a caracterização microbiológica e físico-química da carne de sol no estado de Minas Gerais é escassa. Foi encontrado apenas um registro de trabalho, no qual os autores avaliaram as condições de produção, comercialização, consumo, qualidade microbiológica e características físico-químicas da carne de sol produzida nos municípios de Montes Claros e Mirabela, no estado de Minas Gerais (Cruz, 2010). Com base nesses aspectos, objetivou-se neste estudo avaliar a qualidade físico-química e microbiológica, bem como as condições HST empregadas durante a produção e comercialização da carne de sol no município de Salinas, Minas Gerais, que representa um polo importante de produção desse produto artesanal no estado.

\section{MATERIAL E MÉTODOS}

O município de Salinas (latitude -16²10'13"S; longitude $\left.\quad-42^{\circ} 17^{\prime} 25^{\prime \prime} \mathrm{W}\right) \quad$ localiza-se na mesorregião Norte de Minas Gerais, na microrregião de Salinas. Possui área de $1.862,117 \mathrm{~km}^{2}$, população estimada de 41.301 habitantes e o clima é semiárido, o que favorece a produção de carne de sol (Estatística..., 2018). Foram identificados, no município, 30 estabelecimentos que produziam e comercializavam o produto. Para caracterizar as condições HST de elaboração e comercialização da carne de sol, foram realizados 0 acompanhamento e a descrição de todas as etapas do processamento artesanal junto a cada estabelecimento varejista produtor. Esses dados foram analisados pelo método de distribuição de frequências.

Além dessa caracterização, foram realizadas também análises microbiológicas e físicoquímicas da carne de sol de 10 produtores. De cada produtor, foram coletadas aleatoriamente quatro amostras, totalizando 40 amostras. Os parâmetros físico-químicos avaliados foram umidade, proteína, gordura, cloretos, resíduo mineral fixo e $\mathrm{pH}$, segundo a metodologia descrita na Instrução Normativa $\mathrm{n}^{\circ} .20$ do Ministério da Agricultura, Pecuária e Abastecimento (Mapa) (Brasil, 1999). Para a realização das análises físico-químicas, foi utilizada somente a porção magra das amostras, após a retirada da gordura aparente. As análises microbiológicas realizadas foram pesquisa de Salmonella spp., contagens de Staphylococcus aureus, micro-organismos mesófilos aeróbicos, bolores e leveduras e coliformes totais e termotolerantes, de acordo com as especificações da Instrução Normativa $N^{\circ}$. 62, do Mapa (Brasil, 2003).

\section{RESULTADOS E DISCUSSÃO}

$\mathrm{Na}$ etapa inicial do processamento da carne de sol nos estabelecimentos avaliados, os cortes cárneos eram fatiados em camadas, transformando-se em peças conhecidas regionalmente como "mantas". A espessura dos cortes após o fatiamento era variável, mas, na maioria dos estabelecimentos, produziam-se peças com até três centímetros de espessura. $\mathrm{Na}$ superfície de cada peça, eram realizados cortes pouco profundos, no sentido transversal da fibra, 
com o objetivo de melhorar o processo de salga, que consistia em adicionar e distribuir o sal em toda a superfície da carne. A quantidade de sal utilizada também variava, mas, em $56,52 \%$ dos açougues, eram utilizados entre 31 e $50 \mathrm{~g}$ de sal por quilograma de carne ou, aproximadamente, duas colheres de sopa de sal por quilograma de carne. Os estabelecimentos em que eram adicionados até $30 \mathrm{~g}$ de sal por quilograma de carne representaram $30,43 \%$ do total, enquanto aqueles em que eram adicionados acima de $51 \mathrm{~g}$ de sal correspondiam a $13,05 \%$ do total. Após a salga, a carne era transferida para bandejas brancas de polietileno de alta densidade contendo sal, em quantidade suficiente para cobrir o fundo da bandeja, e armazenada em refrigeradores ou câmaras frias à temperatura de $10^{\circ} \mathrm{C}$. O tempo de salga variava entre seis e 12 horas. Após essa etapa, a carne era retirada das bandejas e colocada em cabines teladas, que eram mantidas à temperatura ambiente, para eliminar o líquido resultante da "purga", termo utilizado pelos produtores para denominar a dessecação da carne pela ação do ar.

O corte cárneo mais utilizado para a produção de carne de sol era a chã de dentro $(69,56 \%)$, conhecida regionalmente como "popão", seguida da alcatra $(13,04 \%)$, maçã de peito $(4,35 \%)$, paleta $(4,35 \%)$, contrafilé $(4,35 \%)$ e filé $(4,35 \%)$.
A preferência pela utilização desse corte aparentemente pode ser justificada pela sua maior maciez, bem como pela distribuição homogênea de sua gordura, o que possibilita a obtenção de um produto considerado regionalmente de alta qualidade sensorial e apreciado pelos consumidores.

A carne utilizada na elaboração da carne de sol era proveniente, na maioria das vezes $(65,22 \%)$, do matadouro municipal, controlado pela Vigilância Sanitária. Em outros açougues $(21,73 \%)$, a carne era oriunda do abate informal, devido às falhas no combate ao comércio clandestino de carnes e demais produtos alimentares pelos órgãos oficiais de inspeção. Em 4,35\% dos estabelecimentos, a carne era adquirida de abatedouros frigoríficos registrados no SIF, que forneciam a carne fresca de melhor qualidade HST. Nos demais estabelecimentos, a carne era proveniente de outros açougues $(4,35 \%)$ ou de outras fontes $(4,35 \%)$. Em relação às condições HST dos estabelecimentos, foi observado que, de um modo geral, os açougues apresentaram instalações, equipamentos e utensílios adequados para a produção e comercialização da carne de sol (Tab. 1), de acordo com as normas da Vigilância Sanitária para o comércio varejista de carnes e produtos cárneos.

Tabela 1. Condições higiênico-sanitárias e tecnológicas (HST) dos estabelecimentos produtores de carne de sol comercializada no município de Salinas, Minas Gerais, em 2015

\begin{tabular}{|c|c|c|c|}
\hline Característica avaliada & $\begin{array}{l}\text { Frequência } \\
\text { relativa }(\%)\end{array}$ & Característica avaliada & $\begin{array}{l}\text { Frequência } \\
\text { relativa }(\%)\end{array}$ \\
\hline Água tratada e esgoto & & Material do teto & \\
\hline Sim & 100,00 & Laje concreto rebocada/pintada & 91,30 \\
\hline Não & 0,00 & Madeira & 4,35 \\
\hline Paredes azulejadas & & PVC & 4,35 \\
\hline Sim & 82,61 & Telas de proteção contra insetos & \\
\hline Não & 17,39 & Sim & 21,74 \\
\hline Separação sanitários/área manipulação & & Não & 78,26 \\
\hline Sim & 78,26 & Controle de moscas & \\
\hline Não & 21,74 & Sim & 34,78 \\
\hline Separação área manipulação/venda & & Não & 65,22 \\
\hline Sim & 60,87 & Controle de baratas & \\
\hline Não & 39,13 & Sim & 69,57 \\
\hline Material da mesa de manipulação & & Não & 30,43 \\
\hline Pedra & 65,22 & Controle de roedores & \\
\hline Pedra e madeira & 8,70 & Sim & 34,78 \\
\hline Pedra e PVC & 26,00 & Não & 65,22 \\
\hline
\end{tabular}


Todos os estabelecimentos possuíam água tratada e esgoto e a grande maioria apresentava paredes azulejadas (82,61\%), sanitários separados do local de elaboração $(78,26 \%)$ e separação entre as áreas de manipulação e de venda $(60,87 \%)$. A separação entre essas áreas é essencial não só em estabelecimentos industriais, mas também naqueles que elaboram produtos artesanais, pois falhas no fluxograma e layout nas etapas de produção podem levar à contaminação cruzada do produto, colocando em risco a saúde dos consumidores. Apesar de haver a separação física entre as áreas de manipulação e de venda na maioria dos açougues, observou-se que, em alguns estabelecimentos $(43,48 \%)$, era permitido o trânsito de consumidores nas áreas de manipulação para que pudessem manusear a carne de sol e avaliar seus atributos, como textura, maciez, entre outros. Esse é um costume ou cultura da região, pois o cliente só adquire o produto se tocá-lo. Porém, essa prática não é recomendada, porque pode levar à contaminação do produto, seja por agentes físicos, químicos ou biológicos, tais como ovos de parasitos e microorganismos indesejáveis.

$\mathrm{Na}$ maioria dos estabelecimentos $(65,22 \%)$, as mesas de manipulação eram de pedra (ardósia ou granito). Para manutenção de condições higiênicas adequadas para a elaboração dos produtos cárneos, os estabelecimentos devem dispor de superfícies constituídas de materiais resistentes, impermeáveis e de fácil limpeza e higienização, tais como o aço inoxidável, durante os trabalhos de manipulação e preparo de matérias-primas e produtos comestíveis. Em relação às condições do teto dos estabelecimentos, observou-se que, em 91,30\% dos casos, ele era constituído de laje de concreto, rebocada e pintada. Apenas um açougue (4,35\%) apresentou forro de PVC (4,35\%), enquanto em outro açougue, observou-se que o teto era revestido em madeira (4,35\%). Segundo a legislação vigente, os estabelecimentos de carnes e derivados devem possuir forro nas dependências onde se realizam trabalhos de recepção, manipulação e preparo de matériasprimas e produtos comestíveis, o qual deve ser constituído de material de fácil limpeza e higienização para evitar o acúmulo de sujeira e micro-organismos que podem contaminar $\mathrm{o}$ produto (Brasil, 2017).

Verificou-se a ausência de telas para proteção contra insetos na maioria dos estabelecimentos $(78,26 \%)$, e, apesar de ser realizado o controle contra moscas $(34,78 \%)$, baratas $(69,57 \%)$ e roedores $(34,78 \%)$ em muitos açougues, nenhum deles possuía um Programa de Controle Integrado de Pragas. Ao se avaliarem os resultados das análises físico-químicas da carne de sol, foi observado que o produto apresentou valores próximos aos observados para a carne bovina in natura resfriada (Hui et al., 2001; Sousa et al., 2006) para todos os parâmetros avaliados, exceto para os teores de cloretos e cinzas (Tab. 2).

Tabela 2. Resultados da avaliação dos parâmetros físico-químicos da carne de sol produzida e comercializada no município de Salinas, Minas Gerais, em 2015

\begin{tabular}{lccrr}
\hline Parâmetros & Média & Coeficiente de variação & Mínimo & \multicolumn{1}{c}{ Máximo } \\
\hline Umidade (\%) & 70,1 & 4,6 & 59,14 & 74,65 \\
Proteína (\%) & 22,3 & 4,9 & 18,88 & 27,33 \\
Gordura (\%) & 2,2 & 54,2 & 0,57 & 5,64 \\
Cloretos (\%) & 3,6 & 45,9 & 1,15 & 11,19 \\
Cinzas (\%) & 5,1 & 45,5 & 1,46 & 12,77 \\
pH & 5,8 & 4,8 & 5,30 & 6,50 \\
\hline
\end{tabular}

O teor médio de umidade encontrado para a carne de sol foi de $70,1 \%$, com valor mínimo de $59,14 \%$ e máximo de $74,65 \%$, demonstrando que o produto possui um alto teor de umidade. Farias (2010), ao avaliar a carne de sol comercializada na cidade de João Pessoa, no estado da Paraíba, encontrou valores semelhantes, variando entre 61,12 e 74,45\%. Evangelista-Barreto et al. (2014) encontraram teores médios de umidade variando entre $58,92 \%$ e $72,16 \%$ na carne de sol comercializada em estabelecimentos do município de Cruz das Almas, na Bahia. Gouvêa et al. (2017), ao avaliarem o efeito da inclusão de diferentes níveis de torta de licuri na dieta de tourinhos Nelore sobre as características físicoquímicas e sensoriais da carne de sol obtida desses animais, encontraram o teor médio de umidade de $67,4 \%$. Por ser produzida de forma 
artesanal, utilizando quantidades não padronizadas de sal, a carne de sol sofre um processo de dessecação leve, o que justifica os teores de umidade encontrados.

A porcentagem média de proteína observada na carne de sol foi de $22,3 \%$, variando entre 18,88 e $27,33 \%$. Esses valores são semelhantes aos teores encontrados para a carne fresca (Hui et al., 2001; Sousa et al., 2006). Gouvêa et al. (2017) encontraram o valor médio de proteína de $20,1 \%$ para a carne fresca e de $23,0 \%$ para a carne de sol.

Em relação à gordura, o valor médio encontrado foi de $2,2 \%$, com valores mínimos e máximos de $0,57 \%$ e $5,64 \%$, respectivamente. O teor de gordura da carne in natura pode variar entre 0,5\% e 10\% (Pardi et al., 1996), de acordo com a raça, o sexo, o manejo, a alimentação, o corte cárneo, a idade, o clima da região, entre outros. Dessa maneira, os resultados encontrados são coerentes e estão dentro da faixa de variação esperada para esse tipo de produto, que passou por um processo de desidratação leve. Os valores de porcentagem de gordura da carne de sol obtidos por Gouvêa et al. (2017) variaram entre 3,9 e 4,3\%, com média de 4,1\%. De forma semelhante ao observado para os teores de proteína, a porcentagem de gordura também é inversamente proporcional ao teor de umidade quando se considera a amostra sem gordura aparente, ou seja, o corte magro da carne.

Nas análises do teor de cloretos, o valor médio encontrado foi de 3,6\%, variando entre $1,15 \%$ e $11,19 \%$. Essa alta variação pode ser explicada pela ausência de padronização na quantidade de sal utilizada na maioria dos açougues, pois esse ingrediente não era pesado. Além disso, como a adição do sal na superfície das peças era feita de forma manual, sua distribuição não era uniforme, variando de acordo com a pressão empregada pelo produtor e com a profundidade dos cortes transversais que eram efetuados na superfície da carne com o intuito de melhorar o processo de salga. O alto coeficiente de variação encontrado para esse parâmetro, de 45,9\%, demonstrou claramente essa falta de padronização. Costa e Silva (1999) também encontraram grande variação nos teores de sal, com valores entre
$3,73 \%$ e $9,79 \%$. Entretanto, Evangelista-Barreto et al. (2014) observaram menor variação nos teores de cloretos da carne de sol comercializada em Cruz das Almas/BA, com valores médios entre 3,47 e $4,95 \%$.

O teor médio de cinzas encontrado para carne de sol foi de $5,1 \%$, com valores mínimos e máximos de $1,46 \%$ e $12,77 \%$, respectivamente. Essa grande variação era esperada pelas mesmas razões apontadas para os teores cloretos, ou seja, falta de padronização no processamento artesanal. Essa média foi inferior ao valor de $8,19 \%$ encontrado por Vieira Neto (1982). O teor de cinzas da carne fresca é de $1 \%$ (Hui et al., 2001), e naturalmente qualquer aumento nesse teor pode ser atribuído à adição de sal. Gouvêa $e t$ al. (2017) encontraram teores médios de cinza de 1,1 para a carne fresca e de $7,4 \%$ para a carne de sol.

O valor médio de $\mathrm{pH}$ encontrado foi de 5,8, com mínimo de 5,3 e máximo de 6,5. Resultados semelhantes foram observados por Gurgel et al. (2014), que encontraram o valor médio de pH 5,7 para carne de sol produzida no Rio Grande do Norte. $\mathrm{O}$ pH da carne pode variar em razão de vários fatores, como falhas nas condições de abate e obtenção da carne, incluindo o abate de animais cansados, estressados, ou processo de maturação da carne ineficiente. Além disso, a heterogeneidade nas condições HST durante as etapas do processamento da carne de sol pode levar ao aumento do $\mathrm{pH}$ da carne devido à deterioração dela e à liberação de compostos nitrogenados pela ação de micro-organismos.

Ao se avaliar a qualidade microbiológica das amostras de carne de sol, coletadas no município de Salinas, foram encontradas altas contagens de todos os micro-organismos pesquisados (Tab. 3). A legislação brasileira não estabelece padrão microbiológico específico para a carne de sol. Dessa maneira, a comparação dos valores encontrados nas análises foi realizada com base no padrão microbiológico estabelecido para produtos cárneos salgados, que determina a pesquisa de Salmonella spp. e Staphylococcus aureus, cujas tolerâncias para amostra indicativa são ausência em $25 \mathrm{~g}$ e contagem máxima de $10^{3} \mathrm{UFC} / \mathrm{g}$, respectivamente (Brasil, 2001). 
Tabela 3. Contagens de micro-organismos presentes na carne de sol comercializada no município de Salinas, Minas Gerais, em 2015

\begin{tabular}{lccc}
\multirow{2}{*}{ Parâmetros } & \multicolumn{3}{c}{ Contagem - UFC/g / NMP } \\
\cline { 2 - 4 } & Mínimo & Máximo & Mediana \\
\hline Micro-organismos mesófilos aeróbicos & $5,35 \times 10^{4}$ & $2,5 \times 10^{8}$ & $2,5 \times 10^{7}$ \\
Staphylococcus aureus & $<1,0 \times 10^{3}$ & $3,00 \times 10^{6}$ & $2,0 \times 10^{3}$ \\
Coliformes totais & $<3$ & $>1100$ & 9,1 \\
Coliformes termotolerantes & $<3$ & $>1100$ & 4,3 \\
Bolores e leveduras & $1,40 \times 10^{3}$ & $7,20 \times 10^{5}$ & $1,73 \times 10^{4}$ \\
\hline
\end{tabular}

Das 40 amostras de carne de sol analisadas, duas (5\%) foram positivas para Salmonella spp. e 16 (40\%) apresentaram contagens de Staphylococcus aureus superiores a $10^{3} \mathrm{UFC} / \mathrm{g}$, sendo, portanto, consideradas impróprias para o consumo humano, de acordo com a legislação vigente (Brasil, 2001). Leite Júnior (2000), ao avaliar a qualidade microbiológica da carne de sol armazenada com e sem refrigeração, comercializada na cidade de Campina Grande/PB, detectou Salmonella spp. em $40 \%$ das amostras comercializadas à temperatura ambiente e em 30\% das armazenadas sob refrigeração. Mennucci (2009) avaliou a qualidade da carne de sol comercializada em 22 "Casas do Norte", localizadas no município de Diadema/SP, e encontrou contagens de Staphylococcus aureus acima de $10^{3} \mathrm{UFC} / \mathrm{g}$ em $50 \%$ das amostras de carne de sol analisadas, além da presença de Salmonella spp. em 9,1\%. Gurgel et al. (2014), ao avaliarem a qualidade da carne de sol comercializada em feiras livres e supermercados ou frigoríficos no Rio Grande do Norte, detectaram a presença de Salmonella spp. em 25\% das amostras e Staphylococcus aureus, em concentrações acima de $10^{3} \mathrm{UFC} / \mathrm{g}$, em $78,75 \%$ delas. Souza et al. (2015) avaliaram a qualidade microbiológica de amostras de carne bovina utilizadas no preparo da carne de sol, em diferentes locais e condições de armazenamento, e encontraram contagens de Staphylococcus spp. variando entre 4,59 e 6,35Log UFC/g.

Considerando que a microbiota encontrada na carne de sol é variável e depende de diversos fatores, tais como qualidade da matéria-prima, quantidade e qualidade do sal, duração da salga, tempo de dessecação, condições HST durante o processamento, embalagem, armazenamento, transporte e comercialização, as altas contagens microbianas encontradas e a presença de Salmonella spp. nas amostras avaliadas podem ser justificadas pela heterogeneidade nas condições HST de produção, que foi observada durante a caracterização dos estabelecimentos e do processamento tecnológico, e refletiu também nos resultados das análises físico-químicas. Apesar de muitos estabelecimentos apresentarem condições adequadas para a obtenção do produto, a falta de padronização das instalações, dos equipamentos e utensílios, associada a falhas de higiene durante o processamento tecnológico da carne de sol, compromete a identidade e a segurança do produto. Segundo Nobre et al. (2010), a não observância de Boas Práticas de Fabricação (BPF) durante o processamento, a elevada atividade de água e o baixo teor de sal no produto são fatores que contribuem para a elevada contagem de micro-organismos na carne de sol. Outro fator importante é a ausência de regulamentação técnica que defina critérios e padrões físico-químicos ou microbiológicos ou que atribua ao produto um memorial descritivo para a elaboração.

A forma de exposição à venda da carne de sol também pode ter levado à sua contaminação, pois muitos comerciantes permitem o manuseio do produto pelos consumidores, que buscam avaliar algumas de suas características, como a textura, por exemplo. Micro-organismos do gênero Staphylococcus podem ser encontrados na pele, nas mucosas, no intestino e no trato respiratório humano, portanto a manipulação pelos consumidores é uma forma importante de contaminação por esse e pelos demais microorganismos pesquisados. Além da manipulação pelos consumidores durante a exposição à venda, a característica cultural observada durante a comercialização da carne de sol, de mantê-la exposta ao ambiente e sem refrigeração, também influenciou as altas contagens de todos os microorganismos pesquisados. Outro fator relevante, que pode justificar os resultados das análises microbiológicas, é o valor médio de umidade, de $70,1 \%$, encontrado nas análises físico-químicas, caracterizando o produto como sendo de alta 
umidade, o que favorece o desenvolvimento de micro-organismos.

A produção de carne de sol é realizada de forma artesanal, nos estabelecimentos varejistas, e sem um padrão definido, pois não existem indústrias desse produto, o que pode justificar as altas contagens de micro-organismos encontradas, bem como a presença de Salmonella spp. Segundo Miranda e Evangelista-Barreto (2012), a contaminação pode ocorrer em diversas etapas do processamento tecnológico, devido ao uso de tecnologia rudimentar na produção, à falta de uniformidade e de um controle rigoroso sobre a matéria-prima utilizada, além da ausência de fiscalização pelos órgãos oficiais competentes. A falta de padrões de identidade e qualidade oficiais e de condições HST adequadas de produção e comercialização desse produto pode oferecer riscos à saúde humana pela veiculação de micro-organismos patogênicos.

Considerando-se as variações locais relacionadas ao modo de preparo da carne de sol e sua influência sobre a qualidade microbiológica e físico-química do produto final, os resultados do presente estudo representam o primeiro passo para consolidar um conhecimento mínimo sobre esse produto típico da região e contribuir para o desenvolvimento de ações e políticas locais de controle sanitário, como uma etapa básica para a busca da certificação de Indicação Geográfica da carne de sol de Salinas.

\section{CONCLUSÃO}

A carne de sol de Salinas é um produto artesanal e apresenta grande variação em relação às características físico-químicas e à qualidade microbiológica, sendo necessário padronizar e controlar as condições higiênico-sanitárias e tecnológicas (HST) de produção e comercialização, para que o seu consumo não coloque em risco a saúde dos consumidores devido à presença de micro-organismos patogênicos.

\section{AGRADECIMENTOS}

Os autores agradecem o apoio da Pró-Reitoria de Pesquisa da Universidade Federal de Minas Gerais (UFMG), da Fundação de Amparo à Pesquisa do Estado de Minas Gerais (Fapemig), do Instituto Federal do Norte de Minas Gerais
(IFNMG) - Campus Salinas, da Fundação de Apoio e Desenvolvimento do Ensino Tecnológico (Fadetec) do IFNMG e da Prefeitura Municipal de Salinas, por proverem fundos para o desenvolvimento e a publicação desta pesquisa e viabilizar infraestrutura para a realização das análises.

\section{REFERÊNCIAS}

BRASIL. Decreto n. 9013, de 29 de março de 2017. Dispõe sobre o regulamento da inspeção industrial e sanitária de produtos de origem animal. Diário Oficial da União, Brasília, Seção 1, 30 mar. 2017

BRASIL. Lei n. 13.680, de 14 de junho de 2018. Lei 13680. Altera a Lei $\mathrm{n}^{\circ} 1.283$, de 18 de dezembro de 1950, para dispor sobre o processo de fiscalização de produtos alimentícios de origem animal produzidos de forma artesanal. Diário Oficial da União, Brasília, Seção 1, 15 jun. 2018.

BRASIL. Ministério da Agricultura, Pecuária e Abastecimento. Instrução Normativa $n^{\circ} 20$, de 21 de julho de 1999. Oficializa os métodos analíticos físico-químicos, para controle de produtos cárneos e seus ingredientes - sal e salmoura. Diário Oficial da União, Brasília, Seção 1, 27 jul. 1999.

BRASIL. Ministério da Agricultura, Pecuária e Abastecimento. Instrução Normativa n. 62, de 26 de agosto de 2003. Oficializa os métodos analíticos oficiais para análises microbiológicas para controle de produtos de origem animal e água. Diário Oficial da União. Brasília, DF, 18 set. 2003. Seção 1, p.14.

BRASIL. Mistério da Saúde. Secretaria de Vigilância Sanitária. Resolução RDC n. 12 de 02 de janeiro de 2001. Aprova o Regulamento Técnico sobre padrões microbiológicos para alimentos. Diário Oficial da União. Brasília, 10 jan. 2001. n.7, E, p.45-53.

COSTA, E.L.; SILVA, J.A. Qualidade sanitária da carne de sol comercializada em açougues e supermercados de João Pessoa - PB. Bol. SBCTA, v.17, p.137-144,1999 
CRUZ, A. L.M. Produção, comercialização, consumo, qualidade microbiológica $e$ características físico-químicas da carne de sol do Norte de Minas Gerais. 2010. $96 f$. Dissertação (Mestrado em Ciências Agrárias) Universidade Federal de Minas Gerais, Montes Claros, MG.

ESTATÍSTICAS por cidade e estado. Rio de Janeiro: IBGE, 2018. Disponível em: <https://www.ibge.gov.br/informacoes-porcidade-e-estado.html>. Acessado em: 22 nov. 2018.

EVANGELISTA-BARRETO, N.S.; MIRANDA, P.C.; BARBOSA, D.C. et al. Condições higiênicas sanitárias da carne de sol comercializada no município de Cruz das Almas, Bahia e detecção de cepas com resistência antimicrobiana. Semin. Cienc. Agrar., v.35, p.1311-1322, 2014.

FARIAS, S.M.O.C. Quality of sun meat in the city of João Pessoa / PB. 2010. 142f. Dissertação (Mestrado em Química e Bioquímica de Alimentos) - Universidade Federal da Paraíba, João Pessoa, PB.

GOUVÊA, A.A.L.; OLIVEIRA, R.L.; LEÃO, A.G. et al. Effects of licury cake in young Nellore bull diets: salted sun-dried meat is preferred rather than fresh meat by consumers despite similar physicochemical characteristics. J. Sci. Food Agric., v.97, p.2147-2153, 2017.

GURGEL, T.E.P.; BANDEIRA, M.G.L.; ABRANTES, M.R. et al. Avaliação da qualidade da carne-de-sol produzida artesanalmente. Rev Inst Adolfo Lutz, v.73, p.208-213, 2014.

HUI, Y.H.; WAI-KIT, N.I.P.; ROGERS, R.W. et al. Meat science and applications. New York: Marcel Dekker, 2001.709p.

LEITE JUNIOR, A.F.S.L. Avaliação da qualidade microbiológica da carne-de-sol, comercializada à temperatura ambiente ou sob refrigeração, em Campina Grande, Paraíba. Hig. Alim., v.14, p.87-92, 2000.
LIRA, G.M.; SHIMOKOMAKI, M. Parâmetros de qualidade da carne-de-sol e dos charques. Hig. Alim., v.12, p.33-35, 1998.

MENNUCCI, T. A. Avaliação das condições higiênico-sanitárias da carne de sol comercializada em "casas do norte" no município de Diadema-SP. 2009. $121 \mathrm{f}$. Dissertação (Mestrado em Saúde Pública) Faculdade de Saúde Pública, Universidade de São Paulo, São Paulo, SP

MIRANDA, P.C.; EVANGELISTA-BARRETO, N.S. Avaliação higiênico-sanitária de diferentes estabelecimentos de comercialização da carnede-sol no município de Cruz das Almas-BA. Rev. Caatinga, v.25, p.166-172, 2012

NOBRE, G.M.C.R.; STROPPA, C.T.; RABELO, P.G.; SANTOS, S.S. Condições higiênico sanitárias de estabelecimentos produtores de carne-de-sol serenada, em município do norte de Minas Gerais. Hig. Alim., v.24, p.3640, 2010.

NÓBREGA， D.M.; SCHNEIDER, I.S. Contribuição da carne de sol visando melhorar sua conservação. Hig. Alim., v.2, p.150-154, 1983.

PARDI, M.C.; SANTOS, I.F.; SOUZA, E.R. et al. Ciência, higiene e tecnologia da carne: tecnologia de carne e de subprodutos processamento tecnológico. Goiana: UFG, 1996.

SOUSA, J.S.; BARRETO, L.C.; FERNANDES, M.V.M. et al. Avaliação da qualidade higiênicosanitária de frangos comercializados na cidade de Salvador-Bahia. Hig. Alim., v.21, p.76-77, 2006.

SOUZA, D.R.; ALMEIDA, A.C.; SOUZA, R.M. e et al. Qualidade microbiológica de cortes cárneos utilizados para elaboração de carne de sol no Norte de Minas Gerais submetidos a diferentes tecnologias de conservação. Rev. Bras. Cienc. Vet., v.22, p.211-215, 2015.

VIEIRA NETO, J. Aspectos tecnológicos da fabricação de carne de sol. Niterói, 1982. 46f. Dissertação (Mestrado em Medicina Veterinária) - Faculdade de Veterinária, Universidade Federal Fluminense, Niterói, RJ. 